\title{
Development and Evaluation of Solvent-Based Cold Patching Asphalt Mixture Based on Multiscale
}

\author{
Shuolei Huang $\mathbb{D}^{1},{ }^{1}$ Junda Ren, ${ }^{1}$ Mingguang Li, ${ }^{1}$ Zhuolin $\mathrm{Li},{ }^{1}$ and Shuiwen $\mathrm{Zhou}^{2}$ \\ ${ }^{1}$ Liaoning Transportation Research Institute Co., Ltd., \\ Key Laboratory of Transport Industry of Expressway Maintenance Technology, Shenyang 110000, China \\ ${ }^{2}$ Sichuan Provincial Transport Department Highway Planning, Survey, Design and Research Institute, Chengdu 611141, China
}

Correspondence should be addressed to Shuolei Huang; h_shuolei@163.com

Received 18 June 2020; Revised 15 September 2020; Accepted 14 October 2020; Published 28 October 2020

Academic Editor: Meng Guo

Copyright (c) 2020 Shuolei Huang et al. This is an open access article distributed under the Creative Commons Attribution License, which permits unrestricted use, distribution, and reproduction in any medium, provided the original work is properly cited.

In order to prepare a kind of high-performance asphalt pavement pit repair material and extend the service life of the road, this paper starts from the microscopic view of the raw materials, uses infrared spectrum, four component analysis method, lying drop method, column wick technology principle, etc. to select the raw materials and determine the initial amount of the cold patching asphalt mixture, and optimizes the formula through the orthogonal test design and adhesion, cohesion, initial stage strength, later strength, residual stability, and other performance indexes, and determines the final formula of cold patching asphalt mixture as follows: the design porosity is $15 \pm 0.5 \%$, compatibilizer is $2.5 \%$, linear SBS modifier is $5 \%$, tackifier is $4 \%$, antistripping agent is $3.5 \%$, and the dosage of diluent $\mathrm{D}$ should be determined according to the ambient temperature. The results show that the performance of the self-made cold patching asphalt mixture is good verified by adhesion grade, strength, high temperature stability, water stability, and other road performance.

\section{Introduction}

The existence of pavement potholes has a serious impact on driving safety and comfort [1]. Therefore, asphalt pavement pothole repair materials and technologies have gradually become the direction and focus of road materials research. For pavement repair with scattered locations and small quantities, hot mix asphalt mixture is used for pavement pit repair, which is not only difficult to produce due to the small quantity but also inconvenient for the construction unit to heat preservation and repair operation of hot mix asphalt, especially in rainy season and winter $[2,3]$. Therefore, the solvent pit cold patching material is widely used and the temperature range is large and mature in technology and has gradually become the research focus of road engineering personnel. It has the advantages of low temperature mixing, simple construction equipment, small environmental pollution, and good social and economic benefits.

Khan et al. [4] determined through precise specific surface areas of four aggregates and seven minerals using
BET (Brunauer, Emmett, and Teller) theory, by measuring the physical adsorption of selected gas vapors on their surfaces and calculating amounts of adsorbed vapors corresponding to monolayer occupancy on the surfaces. Interfacial bond strengths between bitumen and aggregates were also calculated, based on measured surface-free energy components of minerals/aggregates and binders, in both dry and wet conditions. Ferrotti et al. [5] focuses on the experimental characterization of a high-performance cold mix asphalt mixture reinforced with three types of fibers (cellulose, glass-cellulose, and nylon-polyester-cellulose) dosed at two different contents $(0.15 \%$ and $0.30 \%$ by the aggregate weight). The results show that the cellulose-fiber-reinforced material and the standard one showed enhanced performance, allowing the conclusion that they can be more successfully used in maintenance activities. Dash and Panda [6] added some virgin aggregate and rice husk ash as filler material and cement into the mixture. The results show that the increased strength at early aged, at tropical room temperature, was found more dominant due to the water 
evaporation than cement content cold. Geng et al. [7] used cold patching asphalt (CPA) to repair pavement potholes, prepared from a simple mixture of CWO and diesel as the diluent, and the performance of this CPA is evaluated in the laboratory; the results show that CPA has good adhesion to aggregates (>95\%) at CWO contents from $15 \mathrm{wt} \%$ to $35 \mathrm{wt} \%$ in the diluent. In addition, the introduction of CWO in CPAM has no discernible effect on its strength. Wang [8] investigated the effect of reducing moisture susceptibility of cutback asphalt mixture by adding Portland cement and bentonite. Test results showed that adding cement and nanoclay significantly improved the initial strength and cracking resistance and reduced moisture susceptibility. Cheng [9] used the improved boiling method and digital imaging technology to evaluate the cold patching asphalt mixture after boiling. At the same time, "coating ratio" was proposed as the index to evaluate the coating quality. The results show that the improved boiling test results have a good correlation with the results of BBS test and TSR test, indicating that the improved boiling test can be used to evaluate the water damage of CMA effectively. Lv [10] pointed out that the adhesive strength of cold patched asphalt mixture mainly comes from asphalt molecules, and the density of asphalt molecules in cold patched asphalt determines the adhesive strength of asphalt. Bi et al. [11] improved the performance of cold patch by adding waterbased epoxy resin and put forward the evaluation method of initial strength and forming strength of water-based epoxy emulsified asphalt mixture (weeam).

At present, the research on cold patching asphalt mixture at home and abroad is mainly divided into three categories: solvent cold patching asphalt mixture, emulsion cold patching asphalt mixture, and reaction cold patching asphalt mixture $[12,13]$. In emulsified cold patching asphalt mixture, how to control the demulsification time of emulsified asphalt is difficult, and the stability of emulsified asphalt is not very ideal. Therefore, there are big problems in the forming time and storage performance of this type of cold patching asphalt mixture. Reactive cold patching asphalt mixture needs complex reaction of many components and has a certain reaction time. Therefore, this kind of cold patching asphalt mixture generally needs to be mixed on-site and repaired on-site. Although reactive cold patching asphalt mixture has good road performance, the cost of preparing this type of cold patching asphalt mixture is high, and it has not been large-scale application. At the same time, in the existing research of cold patching asphalt mixture, most of the diluents and additives are different, and the micromodification mechanism of the additives is not analyzed, and the aggregates selected are not tested and analyzed from the microlevel to determine which is more suitable for the preparation of cold patching asphalt mixture, resulting in the road performance instability of cold patching asphalt mixture. Therefore, based on the micromechanism of the raw materials, this paper selects and optimizes the raw materials of the cold patching asphalt mixture by the lying drop method and columnar wick technology principle to prepare a high-performance cold patching asphalt mixture.

\section{Materials and Methods}

\subsection{Raw Materials}

2.1.1. The Base Asphalt. The selection of base asphalt for cold patching asphalt mixture shall comply with [14]. In this study, heavy traffic $90^{\#}$ base asphalt is selected as the basic material, and the main performance indexes are shown in Table 1.

2.1.2. Coarse Aggregate, Fine Aggregate, and Mineral Powder. The coarse aggregate and fine aggregate used in this study are one of the granite, basalt, and limestone aggregate determined by subsequent tests. The performance indexes of the coarse aggregate, fine aggregate, and mineral powder meet the requirements of [14].

2.1.3. Diluent. According to the special road use requirements of cold patching asphalt mixture, it should have certain looseness under low-temperature environment, which requires that a certain amount of diluent must be added to the base asphalt to reduce its viscosity so that the mixture after mixing does not condense at low temperature. In this study, four diluents $\mathrm{A}, \mathrm{B}, \mathrm{C}$, and D are selected for research. The performance indexes are shown in Table 2.

2.1.4. Additives. The main function of cold patching additive is to make up and improve some properties of cold patching asphalt lost due to the addition of diluent so that the cold patching asphalt mixture can not only meet the workability under low temperature conditions but also have good road performance after being used in pavement repair. In this study, compatibilizer, tackifier, and antistripping agent (E, F, $\mathrm{G}$, and $\mathrm{H}$ ) were selected to be added into asphalt for test. Specific performance indexes are shown in Tables 3-5.

2.1.5. Modifier. Due to the addition of organic solvent to the cold patching asphalt mixture to dilute the base asphalt, its initial strength, water damage resistance, and high temperature stability are reduced. It is necessary to add modifiers to improve the elasticity, temperature sensitivity, and low temperature ductility of asphalt and improve the adhesion between cold patching asphalt and aggregate, so as to improve the road performance of cold patching asphalt mixture. In this paper, SBS1301 with linear structure is selected as the modifier, and the performance indexes are shown in Table 6.

2.2. Analysis of Microstructure and Properties of Materials. In order to study the modification mechanism of self-made cold patching asphalt mixture and its compatibility with 
matrix asphalt, this paper analyzes the microstructure of tackifier and antistripping agent, further clarifies the modification mechanism of cold patching asphalt, and provides the basis for optimizing material selection.

2.2.1. FTIR Test Results of Tackifier. The infrared spectrum test results of the tackifier used in this paper are shown in Figure 1. The peaks at $3030 \mathrm{~cm}-1$ belong to the $\mathrm{C}-\mathrm{H}$ stretching vibration and the methylene stretching vibration of the aromatic ring of the tackifier; the peak at $1605 \mathrm{~cm}-1$ and the absorption peak at $800-690 \mathrm{~cm}-1$ belong to the out of plane bending vibration of aromatic unsaturated $\mathrm{C}-\mathrm{H}$, all of which indicate that there are aromatic rings in the tackifier. In addition, the peak of $2928 \mathrm{~cm}-1$ is saturated C-H stretching vibration, the peak of $1448 \mathrm{~cm}-1$ and $1374 \mathrm{~cm}-1$ is saturated C- $\mathrm{H}$ bending vibration, and the peak of $1737 \mathrm{~cm}-1$ is carbonyl stretching vibration.

In order to discuss the mechanism of tackifier-modified asphalt, the four components of matrix asphalt, SBS tackifier-modified asphalt, and tackifier-modified asphalt are analyzed, as shown in Table 7.

It can be seen from the above test analysis that the addition of tackifier increases the aromatic content of matrix asphalt, while the mass content of saturated content and asphaltene decreases. This may be due to the addition of aromatic ring in the tackifier, which makes the components of matrix asphalt redistributed. According to the principle of similar compatibility, the tackifier has good compatibility with asphalt. The addition of SBS redistributes the four components of tackifier-modified asphalt, which may be due to SBS. By absorbing the aromatic and saturated components of the modified asphalt, the mass fraction of the aromatic component and the resin is reduced, but the mass fraction of the aromatic component is still greater than the mass fraction of the matrix asphaltene, which indicates that the increase of the mass fraction of the aromatic ring in the tackifier can improve the compatibility of the modified asphalt.

In the system of tackifier, SBS, and asphalt, the addition of tackifier will increase the aromatic content of the system and improve the solubility of asphalt. In addition, SBS absorbs light components to reduce the distance between asphaltenes, thus changing the viscosity of asphalt. As the mass fraction of SBS increases, the number of active nodes of SBS increases and the viscosity enhancer molecules can better adsorb on SBS, which enhances SBS The binding force between polymer network structures improves the restriction of SBS on asphalt, forming a new and stable network structure. The strong interaction between grids in this "network" structure restrains the displacement between asphalt particles, limits the fluidity of asphalt colloid system, and increases its ability to resist certain external forces, thus improving the modification to a certain extent high temperature performance of asphalt.

2.2.2. FTIR Test Results of Antistripping Agent. In order to clarify the modification mechanism of the adhesion effect of antistripping agent on cold patching asphalt, this paper uses
FTIR to test the antistripping agent, and the test results are shown in Figure 2.

As shown in the figure, the peaks at $1550 \mathrm{~cm}-1$ and $1641 \mathrm{~cm}-1$ belong to the vibration absorption of amide, the peaks at 3305 are the characteristic peaks of amino group, and the peaks at $3007 \mathrm{~cm}-1,2953 \mathrm{~cm}-1$, and $2852 \mathrm{~cm}-1$ are the expansion vibration of methylene group, so the sample composition contains polyamide. Compared with the strength of methylene absorption peak, the absorption peaks of amide and amino group are weaker and less, indicating that the alkyl chain of polyamide in the sample is very long.

There is hydrogen bond between the molecules of polyamide, and the polarity of polyamide is very strong, which can produce a strong intermolecular force, has excellent bonding performance, and can form a high-strength bond, which can improve the adhesion performance of cold patching asphalt and stone.

\section{Study on Preparation of Cold Patching Asphalt Liquid and Composition Design of Its Mixture}

\subsection{Preparation of Cold Make-Up Solution}

3.1.1. Preparation Process of Cold Patching Asphalt. The preparation process of cold patching asphalt is basically the same as that of modified asphalt, and the preparation steps are as follows:

(1) Preheat and melt the $90^{\#}$ base asphalt sample (at $150^{\circ} \mathrm{C}$ ), and place it in a shear vessel

(2) Add compatibilizer to the base asphalt, mix evenly, and then add SBS modifier, mix evenly, keep the temperature constant at $160^{\circ} \mathrm{C}$, keep the asphalt, SBS modifier, and shear head together for heat preservation and swelling, and the heat preservation and swelling time is $30 \mathrm{~min}$

(3) The asphalt is heated to $175^{\circ} \mathrm{C}$, the shear is turned on, and the asphalt is sheared at low speed for $30 \mathrm{~min}$ and then at high speed for $1 \mathrm{~h}$

(4) The shear rate was $5500 \mathrm{R} / \mathrm{min}$, and the shear time was $10 \mathrm{~min}$

(5) Lower the temperature of the modified asphalt to $170^{\circ} \mathrm{C}$ and keep it warm for $2 \mathrm{~h}$ so that the modified asphalt can be fully developed

(6) Add antistripping agent and stir for $10 \mathrm{~min}$

(7) When the temperature is reduced to $110^{\circ} \mathrm{C}$, the above modified asphalt is added with the diluent in proportion and sheared at a shear rate of $2000 \mathrm{R} / \mathrm{min}$ for $5 \mathrm{~min}$, and the preparation is completed.

3.1.2. Determination of Diluent and Antistripping Agent Type and Dosage Based on Surface-Free Energy Change. In this paper, a four factor four level orthogonal test is designed to measure the contact angle between the test liquid and the asphalt by the drop method [15-19] and calculate the change value of the surface energy between the low temperature 
TABLe 1: The main performance indexes of $90^{\#}$ base asphalt.

\begin{tabular}{lcc}
\hline Indexes & Experimental data & Specification requirements \\
\hline Penetration $\left(25^{\circ} \mathrm{C}, 5 \mathrm{~s}, 100 \mathrm{~g}\right)$ & 88.3 & $80 \sim 100$ \\
Penetration index PI & 0.47 & $-1.5 \sim+1.0$ \\
Softening point (ring and ball method) $/{ }^{\circ} \mathrm{C}$ & 52.4 & $\geq 44$ \\
Ductility $\left(15^{\circ} \mathrm{C}, 5 \mathrm{~cm} / \mathrm{min}\right)$ & $>150$ & $\geq 100$ \\
Dynamic viscosity of $60^{\circ} \mathrm{C}(\mathrm{Pa} \cdot \mathrm{s})$ & $\geq 140$ & 149 \\
Solubility $\%$ ) & $\geq 99.5$ & 99.5 \\
Residue after heating test in RTFO & & \pm .002 \\
Mass loss $(\%)$ & 62 & $\geq 0.8$ \\
Penetration ratio $25^{\circ} \mathrm{C}(\%)$ & 22 & $\geq 87$ \\
Ductility $10^{\circ} \mathrm{C}(\mathrm{cm})$ & 5 & $\nless 4$ \\
Adhesion grade to coarse aggregate & & \\
\hline
\end{tabular}

TABle 2: Properties of diluent.

\begin{tabular}{lccccc}
\hline Number & Open flash point $\left({ }^{\circ} \mathrm{C}\right)$ & Boiling point $\left({ }^{\circ} \mathrm{C}\right)$ & Toxicity & Smell & Volatilization rate \\
\hline A & $>55$ & $180 \sim 304$ & Low toxicity & Slightly smelly & Moderate \\
$\mathrm{B}$ & $-50 \sim-20^{\circ} \mathrm{C}$ & $30 \sim 205$ & Low toxicity & Slightly smelly & Fast \\
$\mathrm{C}$ & 61 & $170 \sim 222$ & Low toxicity & Slightly smelly & Faster \\
$\mathrm{D}$ & 58 & $161 \sim 200$ & Low toxicity & No peculiar smell & Fast \\
\hline
\end{tabular}

TABLE 3: Basic properties of tackifier.

\begin{tabular}{lcccc}
\hline Project & Appearance & Softening point (global method) $/{ }^{\circ} \mathrm{C}$ & $\begin{array}{c}\text { Acid value } \\
(\mathrm{mg} \cdot \mathrm{KOH} / \mathrm{g})\end{array}$ & $\begin{array}{c}\text { Ash content }(\%) \\
(\mathrm{gl} / 100 \mathrm{~g})\end{array}$ \\
\hline Detection result & Light yellow or dark brown solid & $80 \sim 140$ & $\leq 1.0$ & $\leq 0.1$ \\
\hline
\end{tabular}

TABLE 4: Basic properties of antistripping agent.

\begin{tabular}{lccc}
\hline Number & Density $(\mathrm{g} / \mathrm{cm} 3)$ & Flash point (open) & Physical form \\
\hline $\mathrm{E}$ & 1 & $>300$ & Brown viscous liquid \\
$\mathrm{F}$ & 0.89 & $>200$ & Brown liquid \\
$\mathrm{G}$ & 0.95 & $>300$ & Dark brown viscous liquid \\
$\mathrm{H}$ & 1.02 & $>300$ & Brown viscous liquid \\
\hline
\end{tabular}

TABle 5: Performance index of compatibilizer.

\begin{tabular}{lccc}
\hline Test items & Unit & Detection index & Test standard \\
\hline Kinematic viscosity & $\left(100^{\circ} \mathrm{C}\right) \mathrm{mm} 2 / \mathrm{s}$ & 25 & $\mathrm{~GB} / \mathrm{T} 265$ \\
Open flash point & ${ }^{\circ} \mathrm{C}$ & $\geq 200$ & $\mathrm{~GB} / \mathrm{T} 3536$ \\
Ash content & $\%$ & 0.3 & $\mathrm{~GB} / \mathrm{T} 508$ \\
Water content & $\%$ & 0.01 & $\mathrm{~GB} / \mathrm{T} 260-1977$ \\
Heating reduction & $\left(120^{\circ} \mathrm{C} \times 15^{\prime}\right)$ & $\leq 0.7$ & $\mathrm{~GB} / \mathrm{T} 11409-2008$ \\
Aromatics content & $\%$ & $\geq 90$ & - \\
Appearance & & Coffee color & Visual inspection \\
\hline
\end{tabular}

Table 6: Properties of SBS modifier.

\begin{tabular}{|c|c|c|c|c|c|c|c|c|c|c|}
\hline Number & $\begin{array}{l}\text { Ratio } \\
\text { of S/B }\end{array}$ & $\begin{array}{c}\text { Oil } \\
\text { filling } \\
\text { rate }(\%)\end{array}$ & $\begin{array}{c}\text { Volatile } \\
\text { matter } \\
(\leq \%)\end{array}$ & $\begin{array}{c}\text { Ash } \\
\text { content } \\
(\leq \%)\end{array}$ & $\begin{array}{c}300 \% \\
\text { extension } \\
\text { stress } \\
(\geq \mathrm{MPa})\end{array}$ & $\begin{array}{l}\text { Tensile } \\
\text { strength } \\
(\geq \mathrm{MPa})\end{array}$ & $\begin{array}{l}\text { Elongation at } \\
\text { break }(\geq \%)\end{array}$ & $\begin{array}{c}\text { Permanent } \\
\text { set }(\leq \%)\end{array}$ & $\begin{array}{l}\text { Shore } \\
\text { hardness } \\
\text { (A) }\end{array}$ & $\begin{array}{l}\text { Melt flow } \\
\text { rate } \\
(\mathrm{g} / 10 \mathrm{~min})\end{array}$ \\
\hline $\begin{array}{l}\text { SBS1301 } \\
\text { (YH-791) }\end{array}$ & $30 / 70$ & 0 & 0.7 & 0.20 & 2.0 & 15.0 & 700 & 40 & $\geq 68$ & $0.10-5.00$ \\
\hline
\end{tabular}




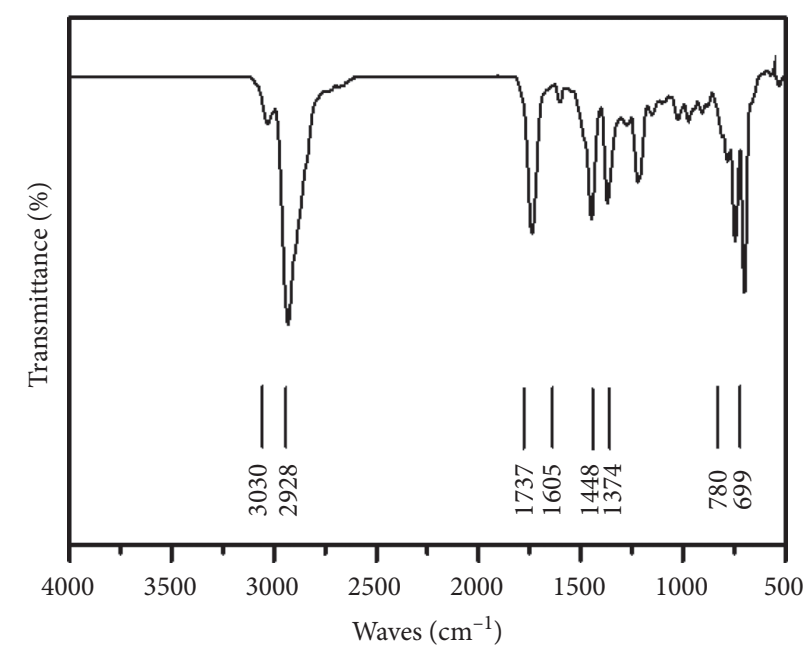

FIGURE 1: Infrared spectrum test results of tackifier.

TABLE 7: Analysis results of four components of base asphalt and tackifier-modified asphalt.

\begin{tabular}{lcccc}
\hline Test sample & $\omega \%$ (saturation fraction) & $\omega \%$ (aromatics) & $\omega \%$ (colloid) & $\omega \%$ (asphaltene) \\
\hline Base asphalt & 23.06 & 31.48 & 40.53 & 4.93 \\
Tackifier-modified asphalt & 6.43 & 49.63 & 41.51 & 2.43 \\
Tackifier-SBS-modified asphalt & 18.22 & 40.46 & 35.47 & 5.85 \\
\hline
\end{tabular}

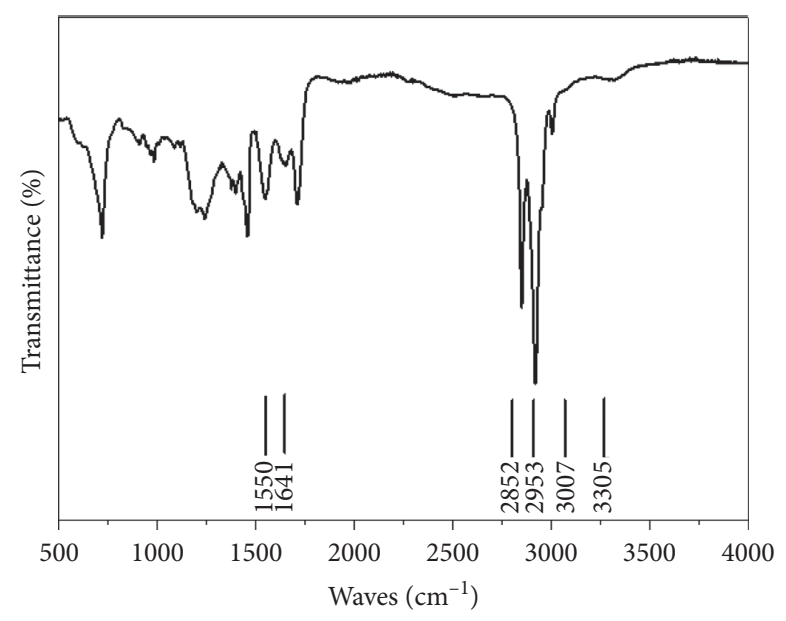

FIGURE 2: Infrared spectrum test results of antistripping agent.

TABLE 8: Change of surface-free energy of asphalt in orthogonal test $\left(\mathrm{m} / / \mathrm{m}^{2}\right)$.

\begin{tabular}{lccccccc}
\hline Test number & Variation value & Test number & Variation value & Test number & Variation value & Test number & Variation value \\
\hline 1 & 2.51 & 5 & 14.05 & 9 & 5.08 & 13 & 6.78 \\
2 & 6.00 & 6 & 18.32 & 10 & 8.37 & 14 & 3.12 \\
3 & 3.30 & 7 & 10.17 & 11 & 6.21 & 15 & 8.52 \\
4 & 8.79 & 8 & 8.08 & 12 & 3.54 & 16 & 9.86 \\
\hline
\end{tabular}

asphalt and the $90^{\#}$ base asphalt. The results are shown in Table 8.

(1) Range analysis: the results are shown in Table 9.
It can be seen from Table 9 that the influence of various factors on the surface-free energy is in the order of diluent type $>$ additive amount $>$ diluent amount $>$ additive type. Therefore, when determining the type and amount of raw 
TABLE 9: Range analysis of surface-free energy change.

\begin{tabular}{lcccc}
\hline Factor & Diluent type & Type of antistripping agent & Diluent content & Dosage of antistripping agent \\
\hline K1 & 5.149 & 7.106 & 9.223 & 4.832 \\
K2 & 12.655 & 8.951 & 8.028 & 6.770 \\
K3 & 5.799 & 7.049 & 4.894 & 8.893 \\
K4 & 7.070 & 7.565 & 8.527 & 10.178 \\
R & 7.506 & 1.902 & 4.339 & 5.346 \\
\hline
\end{tabular}

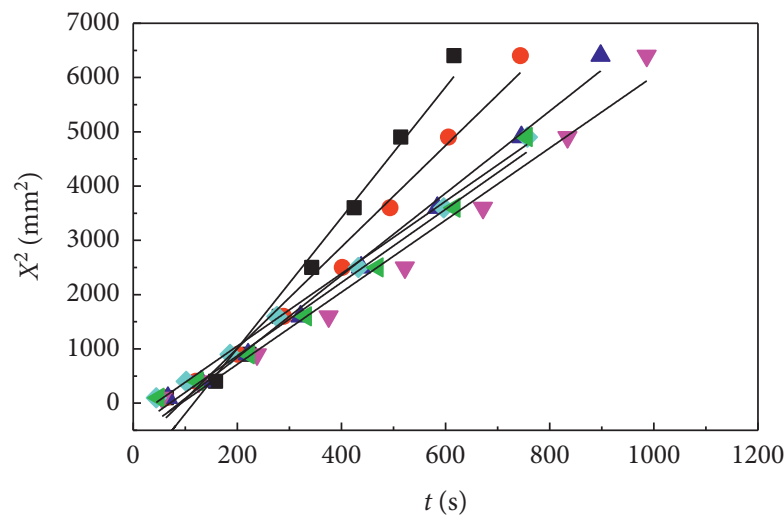

- Hexane-granite-1

- Hexane-granite-2

A Hexane-basalt-1

$\nabla$ Hexane-basalt-2

- Hexane-limestone-1

$\checkmark$ Hexane-limestone-1

(a)

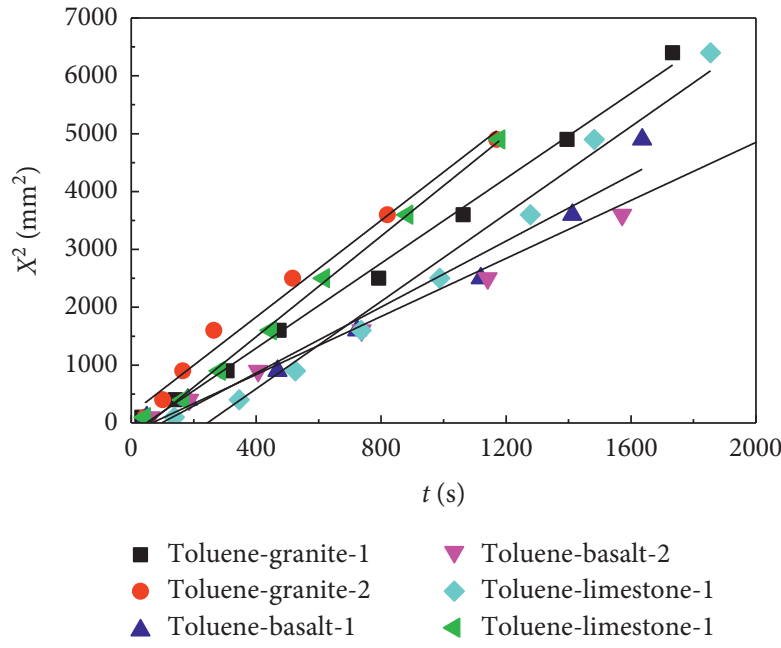

(c)

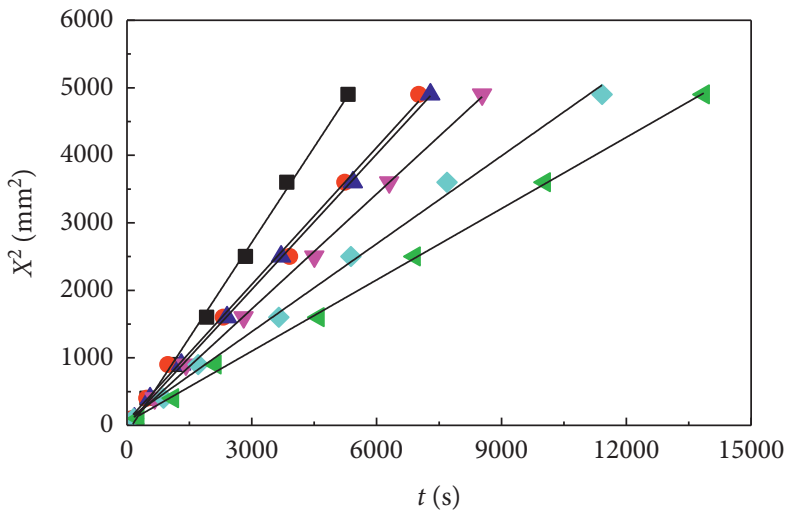

- Diiomethane-granite-1 $\boldsymbol{\nabla}$ Diiomethane-basalt-2

Diiomethane-granite-2 Diiomethane-limestone-1

$\Delta$ Diiomethane-basalt-1 $<$ Diiomethane-limestone-1

(b)

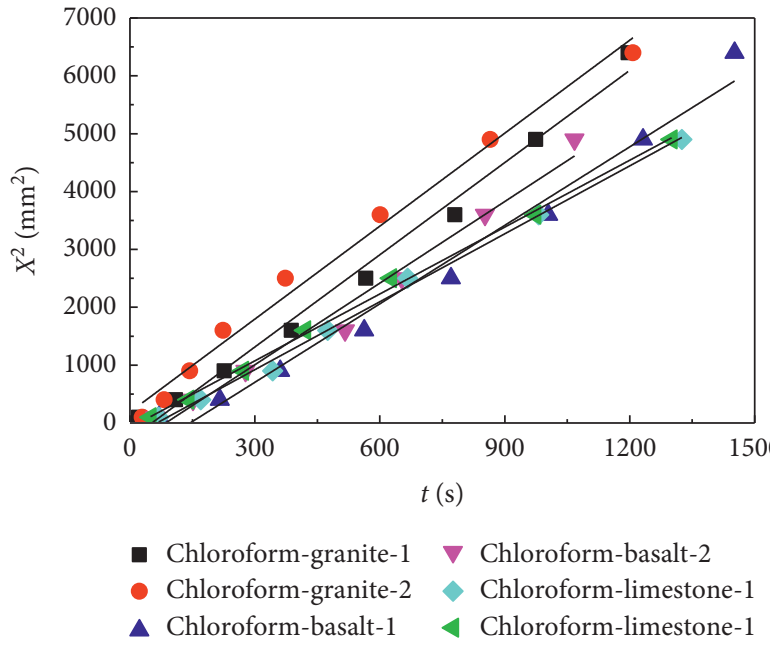

(d)

Figure 3: Relation between impregnation time $t$ of liquid impregnated aggregate powder and square $x^{2}$ of impregnation distance: (a) hexane, (b) diiomethane, (c) toluene, and (d) chloroform.

TABLE 10: Variance analysis of surface-free energy change.

\begin{tabular}{|c|c|c|c|c|c|c|c|}
\hline Index & Factor & SS & $\mathrm{d} f$ & MS & $P$ & Critical value & Significance \\
\hline \multirow{6}{*}{ Surface free energy } & Diluent type & 140.256 & 3 & 46.752 & 0.007 & \multirow{6}{*}{$\begin{array}{c}\alpha=0.10 \\
\alpha=0.01 \\
\alpha=0.025 \\
\alpha=0.05\end{array}$} & \multirow[t]{2}{*}{ Very significant } \\
\hline & Type of antistripping agent & 9.424 & 3 & 3.141 & 0.222 & & \\
\hline & Diluent content & 43.916 & 3 & 14.639 & 0.034 & & Significant \\
\hline & Dosage of antistripping agent & 66.605 & 3 & 22.203 & 0.019 & & \multirow[t]{3}{*}{ Significant } \\
\hline & $\mathrm{e}$ & 3.548 & 3 & 1.183 & 0.007 & & \\
\hline & The sum & 263.749 & 15 & & & & \\
\hline
\end{tabular}


materials, consider in the order of diluent type, additive amount, diluent amount, and additive type.

(2) Analysis of variance: the results are shown in Table 10.

Table 10 shows that $P$ (diluent type) $=0.007<\alpha=0.01$, indicating that the diluent type has a very significant impact on the surface-free energy, $P$ (diluent content) $=$ $0.034<\alpha=0.05$, and $P$ (additive content) $=0.019<\alpha=0.025$, indicating that the diluent content and additive content have a significant impact on the surface-free energy of asphalt.

At the same time, according to the experimental data of the change of the surface-free energy of asphalt, when diluent B is used, the change of the surface-free energy is the largest, and with the increase of the diluent content, the change of the surface-free energy of asphalt increases first and then decreases, when the content is $10 \%$, the change is the largest. When $\mathrm{F}$ antistripping agent is used, the change of surface-free energy is the largest, and with the increase of antistripping agent content, the change of surface-free energy of asphalt increases. When the content of antistripping agent is $4 \%$, the change is the largest.

Therefore, the best ratio of low-temperature asphalt is as follows: diluent $\mathrm{B}$ content is $10 \%$, base asphalt is $80 \%$, and antistripping agent $\mathrm{F}$ content is $4 \%$ (admixture). Considering the safety risks of diluent $\mathrm{B}$, diluent $\mathrm{D}$ is selected for subsequent test.

3.1.3. Measurement and Analysis of Aggregate Surface-Free Energy. According to the technical principle of columnar wick [20-22], the samples of granite, basalt, and limestone are, respectively, impregnated with hexane, and the relation diagram is made, as shown in Figure 3(a). According to the relevant parameters of slope and hexane, the effective radius of capillary is calculated as $R_{\text {Granite }}=3.3 \pm 0.30 \mu \mathrm{m}$, $R_{\text {Basalt }}=2.4 \pm 0.20 \mu \mathrm{m}, \quad$ and $\quad R_{\text {limestone }}=2.2 \pm 0.10$, respectively.

Then, diiomethane, toluene, and chloroform are, respectively, impregnated with granite, basalt, and limestone aggregate powder, and the relation diagram is made, as shown in Figure 4(b-d). The surface energy and its components of various aggregates are calculated, as shown in Table 11.

It can be seen from Table 11 that the surface energy of different aggregates is quite different and the van der Waals force is relatively small, which is mainly caused by different Lewis acid-base forces. The surface energy and its components of limestone aggregate powder are the largest among the three kinds of aggregate, the surface energy of granite is the lowest, and Lewis acid-base force and van der Waals force are the lowest. It shows that the compatibility of limestone aggregate and aggregate will be better, and limestone aggregate is selected for subsequent test.

\subsection{Research on Material Composition Design of Cold Patching Asphalt Mixture}

3.2.1. Material Selection and Mineral Aggregate Grading Design of Cold Patching Asphalt Mixture. The main components of cold patching asphalt mixture are as follows: 90\# base asphalt, modifier, tackifier, compatibilizer, antistripping agent, diluent, and limestone aggregate.

Combined with the research experience of cold patching gradation at home and abroad, according to the environmental characteristics of northern China, the LB-10-1 gradation shown in Table 12 is determined for the preparation of subsequent cold patching asphalt mixture. In order to improve the antistripping performance of cold patching material, $1.5 \%$ cement is added [23].

\subsubsection{Prediction and Determination of the Best Cold Patching} Asphalt Content. In this paper, the empirical formula method is used to design the optimal asphalt content of cold patching asphalt mixture, and the paper trail test is used to adjust the optimal asphalt content.

Based on the California experience formula, the oil stone ratio of cold patching asphalt mixture is calculated by determining the mineral aggregate gradation and the thickness of oil film on the surface of mineral aggregate. Formula (1) is as follows:

$$
\begin{aligned}
h= & P \times(2+0.02 a+0.046 b+0.08 c \\
& +0.14 d+0.3 e+0.6 f+1.6 g),
\end{aligned}
$$

where $a, b, c, d, e, f$, and $g$ are the percentages of passing through the $5 \mathrm{~mm}, 2.5 \mathrm{~mm}, 1.2 \mathrm{~mm}, 0.6 \mathrm{~mm}, 0.3 \mathrm{~mm}$, $0.15 \mathrm{~mm}$, and $0.074 \mathrm{~mm}$ sieve holes, respectively $(\mu \mathrm{m}), h$ is the thickness of asphalt oil film (mm), and $P$ is the ratio of asphalt to stone (\%).

In order to determine the oil stone ratio more accurately, it is necessary to carry out paper trace test and auxiliary judgment. Typical paper trace test results are shown in Figure 4-6.

According to the calculation of empirical formula and the analysis of paper trace test, the optimal initial amount of cold make-up liquid is $4.5 \%$.

3.2.3. Determination of Design Parameters and Material Proportion. In order to determine the design parameters of cold patching asphalt mixture and the proportion of the materials used, the orthogonal test was designed to determine the design void ratio, the amount of diluent, and the amount of various admixtures.

Firstly, four design indexes, i.e., design void ratio, tackifier content, diluent content, and antistripping agent, are selected for sensitivity analysis of cold patching performance. The design orthogonal test level is shown in Table 13.

Using the gradation of cold patching asphalt mixture and the optimal asphalt content of $4.5 \%$ provided above, the preparation of cold patching asphalt mixture with various factors combination is completed, and the performance test of each formula of cold patching asphalt mixture in Table 13 is carried out, the results are as follows.

Adhesion test. The experimental results of 9 formulations are all adhesive grade 5, no significant difference. It is proved 


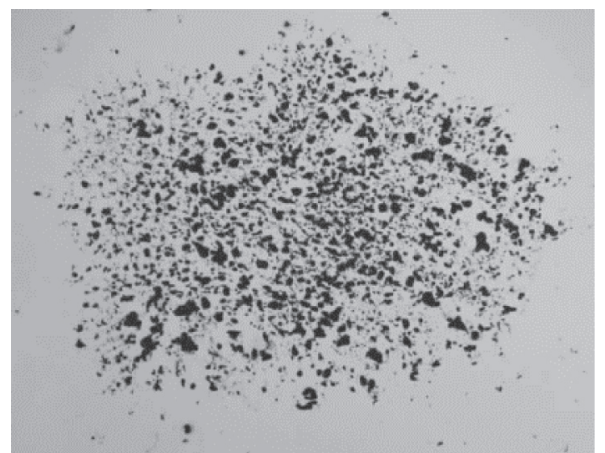

Figure 4: Too little oil.

TABLE 11: Aggregate surface energy and its components $\left(\mathrm{mJ} / \mathrm{m}^{2}\right)$.

\begin{tabular}{lccccc}
\hline Stone & $\begin{array}{c}\text { Surface energy } \\
(\gamma \mathrm{s})\end{array}$ & $\begin{array}{c}\text { van der Waals force } \\
(\gamma \mathrm{sLW})\end{array}$ & $\begin{array}{c}\text { Lewis acid-alkali force } \\
(\gamma \mathrm{sAB})\end{array}$ & $\begin{array}{c}\text { Lewis acid-alkali force } \\
(\gamma \mathrm{s}+)\end{array}$ & $\begin{array}{c}\text { Lewis acid-alkali force } \\
(\gamma \mathrm{s}-)\end{array}$ \\
\hline Granite & 19.10 & 18.20 & 0.90 & 0.05 & 4.29 \\
Basalt & 23.81 & 21.71 & 2.10 & 0.93 & 1.19 \\
Limestone & 28.94 & 21.91 & 7.03 & 1.99 & 6.21 \\
\hline
\end{tabular}

TABLE 12: Screening test results of ore and filler.

\begin{tabular}{lcccccccccccc}
\hline \multirow{2}{*}{ Composite grading } & \multicolumn{10}{c}{ Percentage passing the following sieve (mm) (\%) } \\
& 26.5 & 19 & 16 & 13.2 & 9.5 & 4.75 & 2.36 & 1.18 & 0.6 & 0.3 & 0.15 & 0.075 \\
\hline Upper limit & 100 & 100 & 100 & 100 & 100 & 50 & 25 & 20 & 15 & 10 & 8 & 5 \\
Lower limit & 100 & 100 & 100 & 100 & 80 & 30 & 10 & 8 & 6 & 4 & 3 & 2 \\
Median & 100 & 100 & 100 & 100 & 90 & 40 & 17.5 & 14 & 10.5 & 7 & 5.5 & 3.5 \\
Composite grading & 100.0 & 100.0 & 100.0 & 100.0 & 96.5 & 31.1 & 15.2 & 9.0 & 6.8 & 5.0 & 3.9 & 3.1 \\
\hline
\end{tabular}

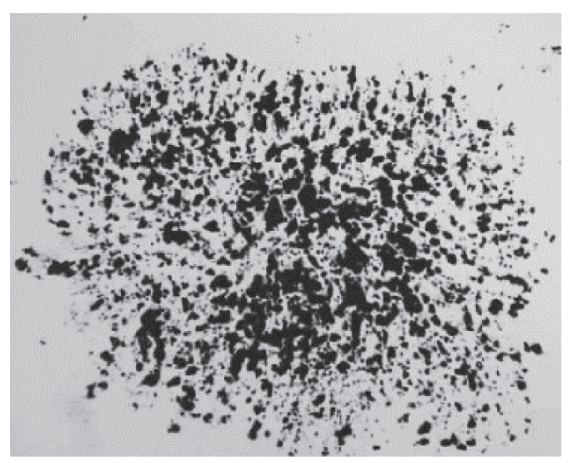

Figure 5: Moderate oil.

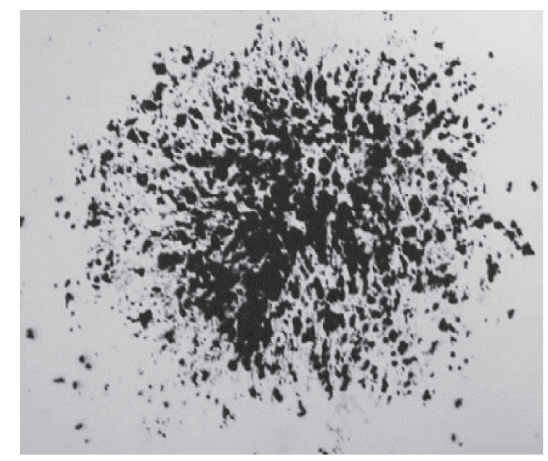

FIgURE 6: Too much oil. 
TABLe 13: $L_{9}\left(4^{3}\right)$ orthogonal test table.

\begin{tabular}{lcccc}
\hline Test number & Factor A & Factor & \\
& Design voidage (\%) & $\begin{array}{c}\text { Factor B } \\
\text { Tackifier content (\%) }\end{array}$ & $\begin{array}{c}\text { Factor C } \\
\text { Diluent content (\%) }\end{array}$ & $\begin{array}{c}\text { D } \\
\text { Dosage of antistripping agent (\%) }\end{array}$ \\
\hline 1 & $10 \pm 0.5$ & 2 & 30 & 2.5 \\
2 & $10 \pm 0.5$ & 3 & 32 & 3.0 \\
3 & $10 \pm 0.5$ & 4 & 34 & 3.5 \\
4 & $15 \pm 0.5$ & 2 & 32 & 3.5 \\
5 & $15 \pm 0.5$ & 3 & 34 & 2.5 \\
6 & $15 \pm 0.5$ & 4 & 30 & 3.0 \\
7 & $20 \pm 0.5$ & 2 & 34 & 3.0 \\
8 & $20 \pm 0.5$ & 3 & 30 & 3.5 \\
9 & $20 \pm 0.5$ & 4 & 32 & 2.5 \\
\hline
\end{tabular}

that the addition of tackifier and modifier in 9 formulations changes the four component ratio of matrix asphalt, and the network structure formed can produce better adhesive performance with aggregate.

Cohesion test. The cohesion study was carried out by the method provided in 《The code for construction of highway asphalt pavement》(JTG F40-2004), and the results are shown in Table 14.

The damage rate of each cold patching asphalt mixture is very low and its cohesion is good. It shows that the 9 kinds of cold patching asphalt mixture are easy to form a whole with the original pavement structure, combined with compactness.

Initial strength test. In this paper, the Marshall specimens, which were compacted 50 times on both sides, were placed in a constant temperature box and kept at $15^{\circ} \mathrm{C}$ to constant temperature. The test results are shown in Figure 7-10.

From Figure 7-10, it can be seen that the smaller the diluent dosage, the higher the tackifier dosage, and the smaller the void ratio, the better the initial strength of the cold patch. Considering the best combination scheme of initial strength, the maximum amount of tackifier should be taken, and the minimum void ratio should be taken, and the sensitivity of void ratio to initial strength is in the middle, but for later strength, the influence of void ratio is far greater than that of other indexes. Therefore, while improving the design void ratio to ensure a rapid strength growth rate and initial strength of cold patch, the void ratio should not be too large to prevent the defect of low initial strength of cold patch, so the median value should be selected.

Later strength and residual stability test. The results of later strength test are shown in Figures 11-18, and the results of residual stability are shown in Tables 15-17.

It can be seen from Figures 11-18 that, for the later strength performance, the influence of the void ratio is far greater than that of diluent and tackifier, and the later strength is a performance index greatly affected by the void ratio. The porosity of $15 \pm 0.5 \%$ is slightly better than $20 \pm 0.5 \%$, the difference is not significant. When the void ratio is $10 \pm 0.5 \%$, the later strength indexes are obviously lower. Therefore, it is suggested that the void ratio of cold patching asphalt mixture should be controlled between 15\% and $18 \%$, which can not only meet the requirements of initial strength but also make the later strength of the mixture higher.

From Tables 15 to 17 , it can be seen that the sensitivity factors of residual stability are mainly tackifier and antistripping agent, which show that with the increase of the content of tackifier and antistripping agent, the adhesion force of cold patching asphalt mixture is higher and higher. This is because the performance of the original modified asphalt is destroyed after adding diluent. The addition of additives improves the performance of cold make-up fluid and makes the cold patching asphalt mixture have better adhesion. Moreover, the influence of tackifier on the residual stability of cold patching asphalt mixture is far greater than that of other materials. When the content of tackifier is $3.5 \%$ and the content of antistripping agent is $3.5 \%$, the residual stability of cold patching asphalt mixture is the highest.

Comparison and selection of optimum design of cold patching asphalt mixture. Through the analysis of the key factors affecting the performance of cold patching asphalt mixture, the voidage, additives, diluents, etc. were screened, and the proportion of cold patching asphalt mixture was gradually optimized. Finally, the design void ratio is $15 \pm 0.5 \%$, compatibilizer $2.5 \%$, linear SBS modifier $5 \%$, tackifier $4 \%$, antistripping agent $3.5 \%$, and diluent $\mathrm{D}$ content should be determined according to the use environment temperature.

\section{Performance Evaluation of Cold Patching Asphalt Mixture}

On the basis of the composition, gradation type and optimum asphalt consumption of the cold patching asphalt mixture determined above, according to the provisions of 《Tinished asphalt pavement pit cold patching material》(JT/T972-2015), 《Technical code for construction of highway asphalt pavement》(JTG F40-2004), and referring to the test methods and standards of some hot mix asphalt mixtures, the strength, high temperature performance and water damage resistance of cold patching asphalt mixtures are evaluated. 
TABLE 14: Data sheet of cohesion test.

\begin{tabular}{|c|c|c|c|c|c|c|c|c|c|}
\hline Test number & 1 & 2 & 3 & 4 & 5 & 6 & 7 & 8 & 9 \\
\hline Residue rate (\%) & 99.7 & 99.8 & 99.6 & 99.7 & 100.1 & 99.9 & 99.9 & 100.0 & 100.0 \\
\hline Breakage rate $(\%)$ & 0.3 & 0.2 & 0.4 & 0.3 & -0.1 & 0.1 & 0.1 & 0 & 0 \\
\hline
\end{tabular}

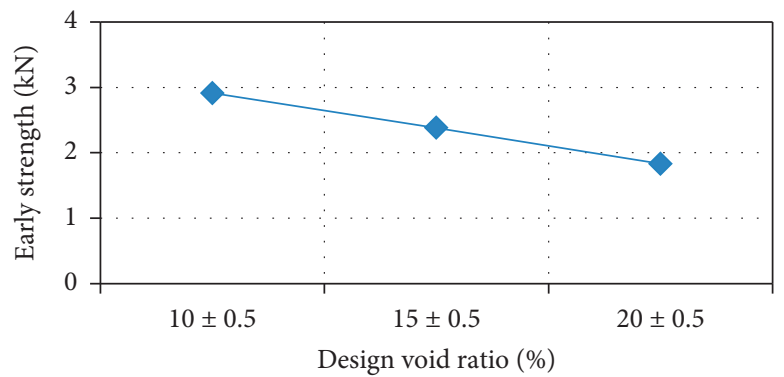

FIGURE 7: Relationship between early strength and design void ratio.

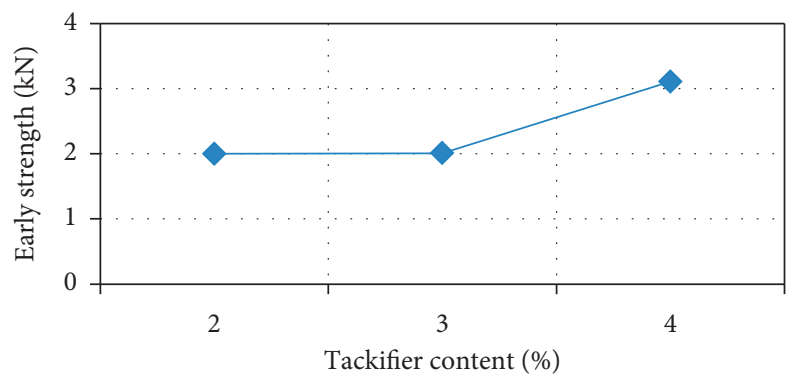

Figure 8: Relationship between early strength and amount of tackifier.

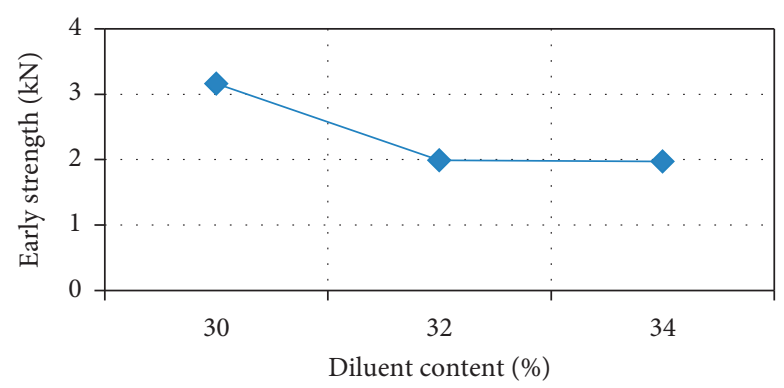

FIGURE 9: Relationship between early strength and diluent dosage.

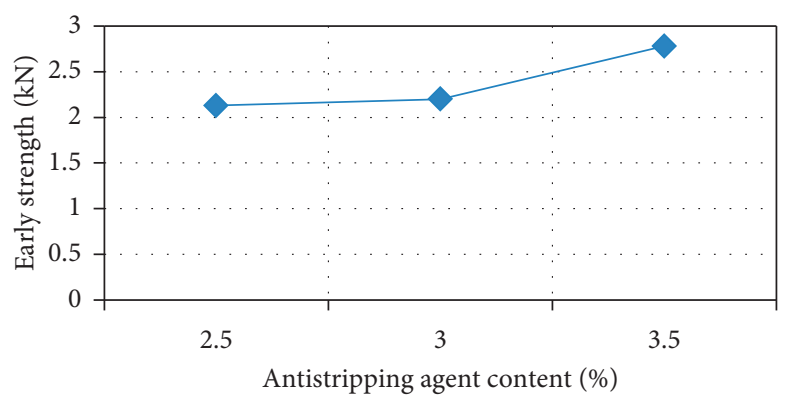

FIGURE 10: Relationship between early strength and antistripping agent dosage. 


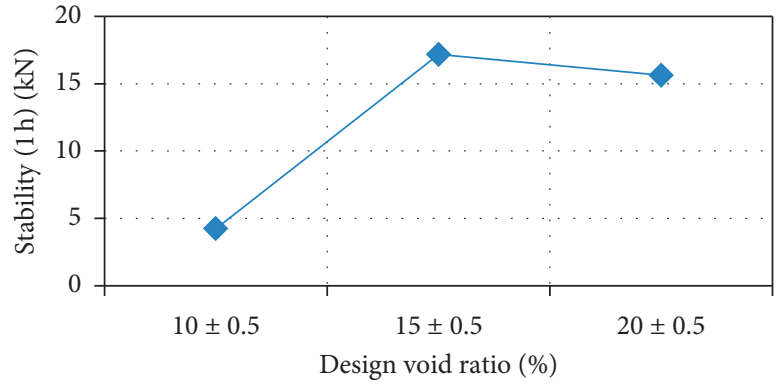

FIgURE 11: Relationship between late strength $(60 \mathrm{~min})$ and design porosity.

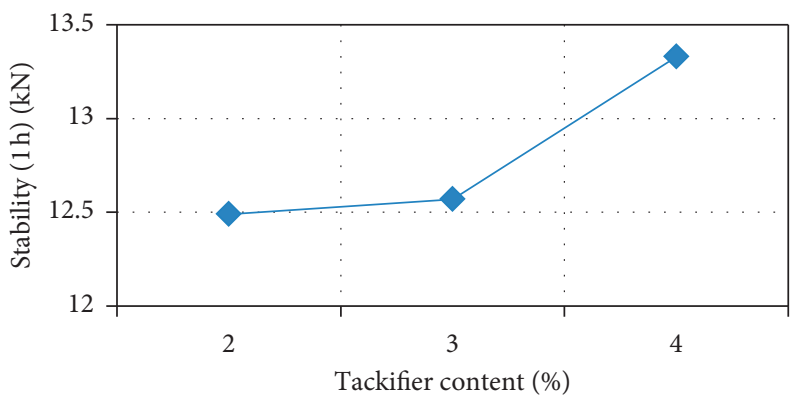

Figure 12: Relationship between late strength $(60 \mathrm{~min})$ and tackifier content.

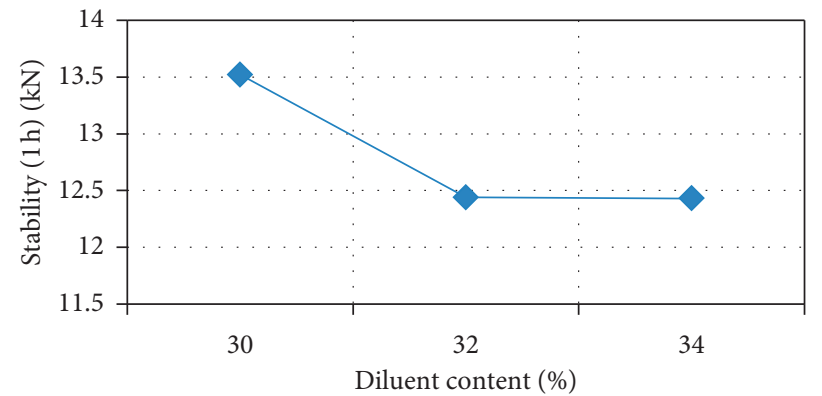

FIgURE 13: Relationship between late strength $(60 \mathrm{~min})$ and diluent dosage.

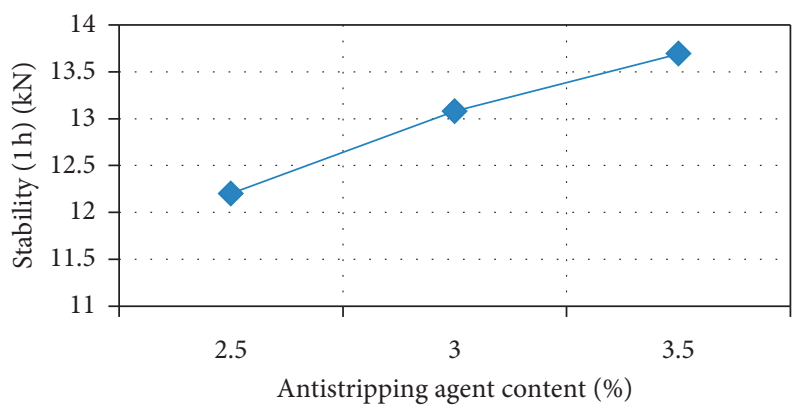

FIgURE 14: Relationship between late strength $(60 \mathrm{~min})$ and antistripping agent dosage. 


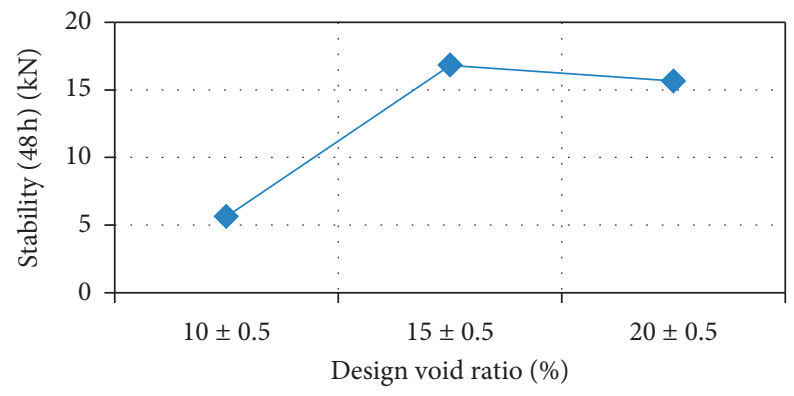

FIgURE 15: Relationship between late strength ( $48 \mathrm{~h})$ and design porosity.

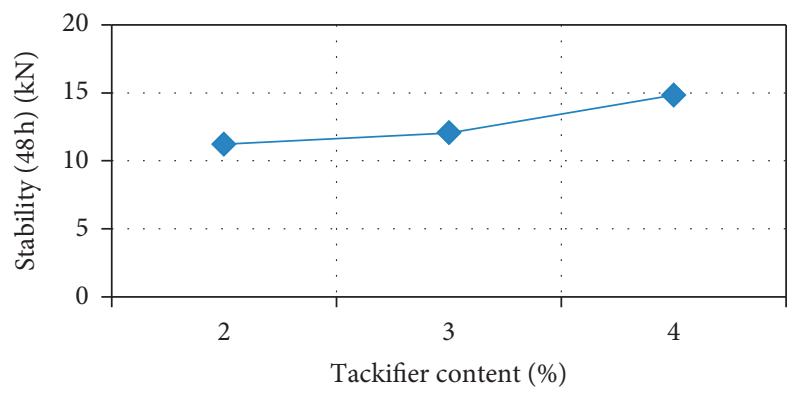

FiguRE 16: Relationship between late strength $(48 \mathrm{~h})$ and tackifier content.

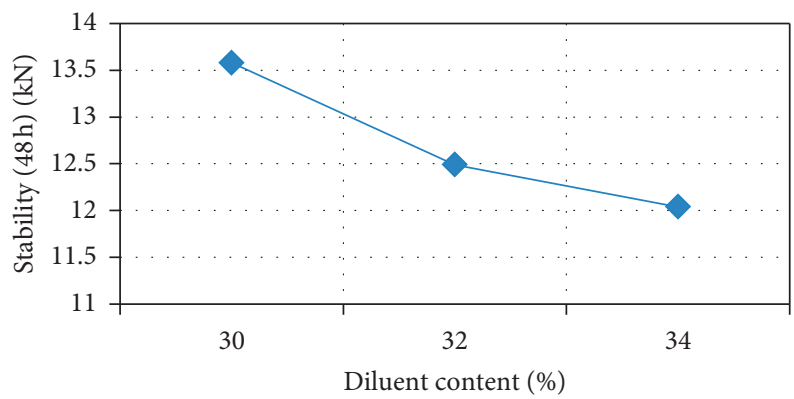

FIgURE 17: Relationship between late strength (48 h) and diluent dosage.

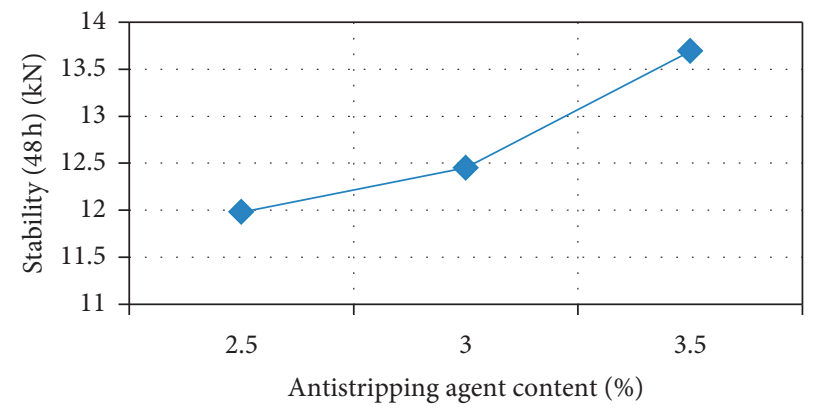

FIGURE 18: Relationship between late strength (48 h) and antistripping agent dosage.

4.1. Adhesion Grade. The adhesive grade of the cold patching asphalt mixture prepared after the optimized ratio is grade 5, and the product conforms to $\ll$ The technical requirements of finished cold patching material for asphalt pavement pit and groove 》(JT/T 972-2015).
4.2. Strength Test. The strength of cold patching asphalt mixture was tested by the methods of stability and residual stability in 《Finished cold patching material for asphalt pavement pit and groove $\gg \mathrm{JT} / \mathrm{T}$ 972-2015. Data result is shown in Table 18. 
TABLE 15: Sensitivity analysis of cold patching asphalt mixture residual stability test.

\begin{tabular}{lcccr}
\hline Test number & Factor A & Factor & Factor B \\
& Design void ratio & Tackifier content & Diluent content & $\begin{array}{c}\text { Factor D } \\
\text { Dosage of antistripping agent }\end{array}$ \\
\hline K1 & 99.163 & 87.470 & 95.610 & 94.260 \\
K2 & 97.620 & 93.380 & 97.220 & 92.270 \\
K3 & 100.160 & 116.093 & 104.113 & 110.413 \\
Range & 2.540 & 28.623 & 8.503 & 18.143 \\
\hline
\end{tabular}

TABLE 16: Variance analysis results of cold patching asphalt mixture residual stability test.

\begin{tabular}{lccc}
\hline Factor & Sum of squares of deviations & Freedom & \\
\hline Design void ratio & 9.827 & 2 & F Ratio \\
Tackifier content & 1370.119 & 2 & 0.019 \\
Diluent content & 122.417 & 2 & 2.614 \\
Antistripping agent content & 594.071 & 2 & 0.234 \\
Error & 2096.43 & 8 & 1.133 \\
\hline
\end{tabular}

TABLE 17: Optimal parameter combination scheme and sensitivity sequence of strength stability in later stage of cold feed.

\begin{tabular}{|c|c|c|c|c|c|}
\hline \multirow[b]{2}{*}{$\begin{array}{l}\text { Performance } \\
\text { index }\end{array}$} & \multicolumn{4}{|c|}{ Design parameters } & \multirow[b]{2}{*}{ Parameter sensitivity ranking } \\
\hline & $\begin{array}{l}\text { Design void } \\
\text { ratio }\end{array}$ & $\begin{array}{l}\text { Tackifier } \\
\text { content }\end{array}$ & $\begin{array}{l}\text { Diluent } \\
\text { content }\end{array}$ & $\begin{array}{l}\text { Antistripping agent } \\
\text { content }\end{array}$ & \\
\hline Initial strength & 2 & 3 & 1 & 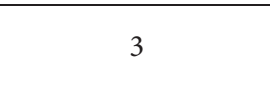 & $\begin{array}{c}\text { Diluent }>\text { void ratio }>\text { tackifier }>\text { antistripping } \\
\text { agent }\end{array}$ \\
\hline Late stability (1 h) & 2 & 3 & 1 & 3 & $\begin{array}{c}\text { Void ratio }>>\text { diluent }>\text { antistripping } \\
\text { agent }>\text { tackifier }\end{array}$ \\
\hline $\begin{array}{l}\text { Late stability } \\
(48 \mathrm{~h})\end{array}$ & 2 & 3 & 1 & 3 & $\begin{aligned} \text { Void ratio } & >>\text { tackifier }>\text { antistripping } \\
\text { agent } & \geq \text { diluent }\end{aligned}$ \\
\hline Residual stability & 3 & 3 & 3 & 3 & Tackifier $>$ antistripping agent $>$ diluent $>$ void \\
\hline
\end{tabular}

TABLE 18: Strength test results.

\begin{tabular}{lcccccccc}
\hline Test number & 1 & 2 & 3 & 4 & 5 & 6 & Average value & Residual stability (\%) \\
\hline Stability $(1 \mathrm{~h}, \mathrm{kN})$ & 17.83 & 16.92 & 17.55 & 18.04 & 17.38 & 17.2 & 17.5 & 101.7 \\
Stability $(48 \mathrm{~h}, \mathrm{kN})$ & 17.26 & 17.82 & 17.69 & 17.72 & 18.03 & 18.45 & 17.8 & \\
\hline
\end{tabular}

According to 《The finished cold patching material for asphalt pavement pit and groove $\gg J T / T 972-2015$, the stability shall be greater than $3 \mathrm{kN}$ and the residual stability shall be greater than $85 \%$. The test results show that the stability of the self-made cold patching asphalt mixture is more than $3 \mathrm{kN}$, the strength meets the requirements, and the residual stability is also high. It is preliminarily verified that the cold patching asphalt mixture has good water damage resistance. In the future, the freeze-thaw split test and mist dynamic water erosion test will be used for further test.

4.3. High Temperature Stability. Because there are still some diluents in the cold patching asphalt mixture rut after forming, the dynamic stability value is too low when the rut test method suitable for hot patching asphalt mixture is used to test its high-temperature stability. Therefore, in this paper, the test method is improved to place the rutting test piece after cold patch rolling in the oven for curing and conduct the rutting test after the diluent volatilizes. The test results are shown in Table 19.

According to the test results in Table 19, the self-made cold patching asphalt mixture has good high-temperature performance, which is equivalent to the performance of ordinary hot patching asphalt mixture and meets the road performance requirements of cold patching asphalt mixture.

\subsection{Water Stability}

4.4.1. Freeze-Thaw Split Test. Because the $40^{\circ} \mathrm{C}$ water bath temperature can reflect the actual environment temperature when the cold patching asphalt mixture produces water damage, at the same time, it can solve the problem of loose collapse of the cold patching asphalt mixture due to the existence of diluent when the water bath temperature is too high, so as to ensure the smooth progress of the test. In this paper, the water bath temperature of freeze-thaw splitting test in 《Test code for asphalt and asphalt mixture of 
TABLe 19: High-temperature stability test results.

\begin{tabular}{lccc}
\hline Test number & Dynamic stability $($ second $/ \mathrm{mm})$ & 45 minrut depth $(\mathrm{mm})$ & $60 \mathrm{minrut}$ depth $(\mathrm{mm})$ \\
\hline 1 & 6750 & 0.790 & 0.794 \\
2 & 6366 & 0.805 & 0.807 \\
3 & 5857 & 0.852 & 0.852 \\
4 & 6095 & 0.826 & 0.827 \\
5 & 5353 & 0.865 & 0.865 \\
6 & 5687 & 0.857 & 0.859 \\
\hline
\end{tabular}

TABle 20: Freeze-thaw split test results.

\begin{tabular}{lcccc}
\hline \multirow{2}{*}{ Test number } & \multicolumn{2}{c}{ Splitting tensile strength $(\mathrm{MPa})$} & \multirow{2}{*}{ Average splitting tensile strength (MPa) } \\
& 1 & 2 & 3 & TSR\% \\
\hline Without freeze-thaw cycle $(\mathrm{kN})$ & 0.2725 & 0.2418 & 0.2067 & 0.24 \\
After freeze-thaw cycle $(\mathrm{kN})$ & 0.2568 & 0.2254 & 0.2025 & 0.23 \\
\hline
\end{tabular}

Highway Engineering》(JTG E20-2011)is modified to $40^{\circ} \mathrm{C}$. The test results are shown in Table 20.

The test results in Table 20 show that the freeze-thaw splitting strength ratio of the self-made cold patching asphalt mixture in this paper is $95 \%$, which meets the requirement that the freeze-thaw splitting strength ratio of the common hot mix asphalt mixture should not be less than $70 \%$, indicating that its water damage resistance is good.

4.4.2. MIST Hydrodynamic Scour Test. Mist water sensitivity tester (Figure 19) can simulate the scour effect of wheel on wet road and the high temperature and periodic pressure environment and detect the water stability in about 3 hours. The pressure is cycled from 0 to 40 PSI, and the pores in the sample are continuously pressurized and depressurized. The high-temperature water in and out of the pores not only produces the scour effect similar to that of the actual tire rolling over the road but also accelerates the damage rate of the integrity of the sample and the adhesion between the aggregate and the adhesive caused by this effect. Under high pressure, water acts between the aggregate and binder in this way, which accelerates the peeling rate. The most obvious change is the relative density of wool volume. The test pieces of MIST are generally prepared by the rotary compactor, in order to keep the consistency with the data of freeze-thaw splitting test, and the Marshall specimen is used instead. The test results are shown in Table 21.

The test standard is that the void ratio of cold patching asphalt mixture before and after treatment by mist is not more than 1.5\%; no obvious peeling and damage on the appearance; the splitting strength shall not be less than $80 \%$. If two of the above conditions meet the requirements, it can be judged as qualified and insensitive to moisture. The ratio of freeze-thaw splitting strength of self-made cold patching asphalt mixture and commercial cold patching asphalt mixture is $93.7 \%$ and $82.7 \%$, respectively, which meets the requirements of detection standard no less than $80 \%$. The percentage (\%) of voidage (before and after) difference is 0.8 and 1.0, respectively, which is no more than $1.5 \%$ meeting the requirements of the test standard. There is no obvious peeling and damage in appearance, but the self-made cold patching asphalt mixture is better. $93.7 \%$ of freeze-thaw splitting strength ratio of the self-made sample MIST test is close to that of the freeze -thaw splitting test, so the water stability of the cold patched asphalt mixture is good.

\section{Results and Discussion}

(1) The infrared spectrum analysis of the tackifier was supplemented by the four components analysis of base asphalt, SBS tackifier-modified asphalt, and tackifier-modified asphalt. The results showed that the addition of tackifier increased the aromatic content of the base asphalt, so the tackifier had good compatibility with asphalt; SBS absorbs the aromatics and saturates of the asphalt modified by tackifier. The increase of the mass fraction of aromatic ring in the tackifier can improve the compatibility of the modified asphalt.

(2) The results of IR spectrum analysis of antistripping agent show that the alkyl chain of polyamide in the sample is very long, and there is hydrogen bond between the molecules of polyamide, and the polarity of polyamide is very strong, which can produce very strong intermolecular force, has excellent bonding performance, and can form a high-strength bond, which can improve the adhesion performance of cold patching asphalt and stone.

(3) Based on the principle of lying drop test and the orthogonal test design method, the free energy of asphalt surface is measured, so as to determine the material selection and preliminary mixing proportion of diluent and antistripping agent. Based on the principle of columnar wick technology, the free energy of aggregate surface is measured, and it is determined that limestone aggregate is most suitable for the preparation of cold patching asphalt mixture.

(4) The orthogonal test is used to optimize the material composition design of cold patch asphalt mixture. The performance test results show that, in order to 


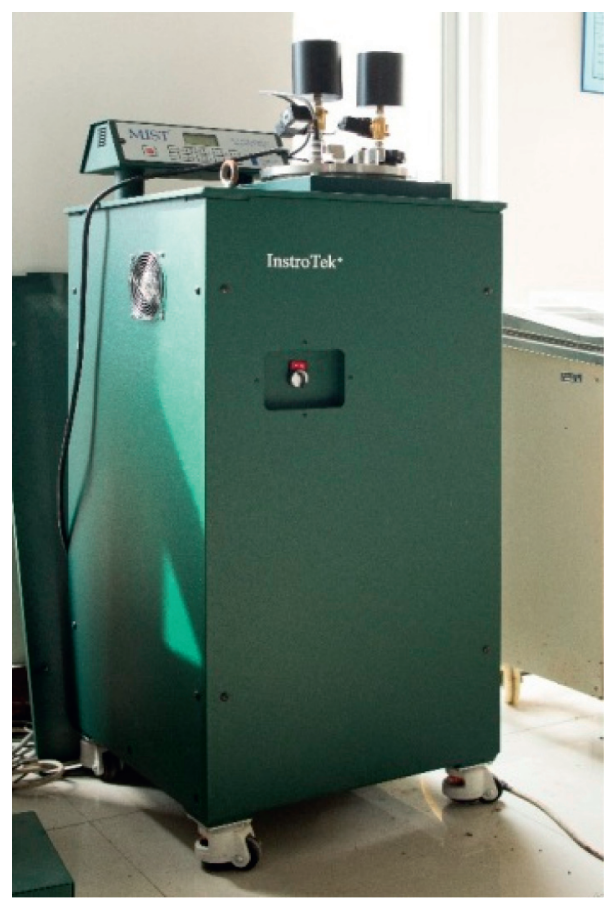

FIGURE 19: MIST water sensitivity tester.

TABLE 21: Test results of dynamic water erosion of MIST.

\begin{tabular}{lcc}
\hline Number index & Self-made sample & Commercial samples \\
\hline Splitting strength ratio of freeze-thaw \% & 93.7 & 82.7 \\
Percentage of voidage difference (before and after) (\%) & 0.8 & 1.0 \\
Visual inspection & No abnormality & No abnormality \\
\hline
\end{tabular}

ensure the strength requirements of cold patch asphalt mixture, the void ratio should be between $15 \%$ and $18 \%$, and the content of antistripping agent has great influence on the water stability, and its content should be controlled between $3 \%$ and $5 \%$.

(5) The design parameters and material proportion of cold patching asphalt mixture are optimized by orthogonal test. The results show that the design void ratio is $15 \pm 0.5 \%$, compatibilizer is $2.5 \%$, linear SBS modifier is $5 \%$, tackifier is $4 \%$, antistripping agent is $3.5 \%$, and diluent $\mathrm{D}$ should be determined according to the use environment temperature. The properties of the cold patching asphalt mixture meet the requirements of the hot mix asphalt mixture.

\section{Data Availability}

The data used to support the findings of this study are included within the article.

\section{Conflicts of Interest}

The authors declare no conflicts of interest.

\section{Authors' Contributions}

Shuolei Huang and Junda Ren conceived and designed the experiments; Mingguang Li performed the experiments; Shuiwen Zhou and Zhuolin Li analyzed the data; and Shuolei Huang and Junda Ren wrote the paper.

\section{Acknowledgments}

The research was funded by Research on Pit Repair Material of High-Performance Asphalt Pavement approved by Liaoning Provincial Department of Communications.

\section{References}

[1] Q. Dai, "Discussion on the repair measures of the potholes and cracks in the highway pavement," Sichuan Cement, vol. 1, p. 351, 2020.

[2] J. Wang, Study on Design and Durability of Cold Patching Asphalt Mixture, Harbin University of Technology, Harbin, China, 2016.

[3] X. Xing, Study on the Preparation and Properties of Cold Patching Asphalt Mixture, Southeast University, Nanjing, China, 2016.

[4] A. Khan, P. Redelius, and N. Kringos, "Evaluation of adhesive properties of mineral-bitumen interfaces in cold asphalt 
mixtures," Construction and Building Materials, vol. 125, pp. 1005-1021, 2016.

[5] G. Ferrotti, E. Pasquini, and F. Canestrari, "Experimental characterization of high-performance fiber-reinforced cold mix asphalt mixtures," Construction and Building Materials, vol. 57, pp. 117-125, 2014.

[6] S. S. Dash and M. Panda, "Influence of mix parameters on design of cold bituminous mix," Construction and Building Materials, vol. 191, pp. 376-385, 2018.

[7] L. Geng, Q. Xu, X. Yu, C. Jiang, Z. Zhang, and C. Li, "Laboratory performance evaluation of a cold patching asphalt material containing cooking waste oil," Construction and Building Materials, vol. 246, p. 117637, 2020.

[8] Z. Wang, "Early-stage road property improvements of cold recycled asphalt emulsion mixture with microwave technology," Cleaner Production, vol. 263, 2020.

[9] L. Cheng, "Measuring moisture susceptibility of Cold Mix Asphalt with a modified boiling test based on digital imaging," Construction and Building Materials, vol. 105, pp. 391-399, 2016.

[10] W. Lv, Characteristics and Preparation Technology of Cold Laid Asphalt Material, Huadong Gonglu, Kaohsiung, Taiwan, 2002.

[11] Y. Bi, R. Li, S. Han, J. Pei, and J. Zhang, "Development and performance evaluation of cold-patching materials using waterborne epoxy-emulsified asphalt mixtures," Materials, vol. 13, no. 5, p. 1224, 2020.

[12] L. Cui, Study on Cold Patching Asphalt Mixture, Chang'an University, Xi'an, China, 2006.

[13] F. Li, "Research on composition design of cold patching asphalt mixture," Journal of Wuhan University of Technology, vol. 32, no. 14, pp. 79-82, 2010.

[14] People's Communications Press, Industrial Standard of the People's Republic of China. JTG F40-2004 Technical Code for Construction of Highway Asphalt Pavement, People's Communications Press, Beijing, China, 2004.

[15] F. M. Fowkes, "Attractive forces at interfaces," Industrial \& Engineering Chemistry, vol. 56, no. 12, pp. 40-52, 1964.

[16] R. J. Good, "Contact angle, wetting, and adhesion: a critical review," Journal of Adhesion Science and Technology, vol. 6, no. 12, pp. 1269-1302, 1992.

[17] C. J. Van Oss, R. J. Good, and M. K. Chaudhury, "Additive and nonadditive surface tension components and the interpretation of contact angles," Langmuir, vol. 4, no. 4, pp. 884-891, 1988.

[18] C. J. Van Oss, M. K. Chaudhury, and R. J. Good, "Interfacial Lifshitz-van der Waals and polar interactions in macroscopic systems," Chemical Reviews, vol. 88, no. 6, pp. 927-941, 1988.

[19] Y. Tan and M. Guo, "Using surface free energy method to study the cohesion and adhesion of asphalt mastic," Construction and Building Materials, vol. 47, pp. 254-260, 2013.

[20] E. W. Washburn, “The dynamics of capillary flow," Physical Review, vol. 17, no. 3, p. 273, 1921.

[21] E. Chibowski, "Solid surface free energy components determination by the thin-layer wicking technique," Journal of Adhesion Science and Technology, vol. 6, no. 9, pp. 1069-1090, 1992.

[22] C. J. Van Oss, Interfacial Forces in Aqueous Media, CRC Press, Boca Raton, FL, USA, 2006.

[23] M. Guo and Y. Tan, "Interaction between asphalt and mineral fillers and its correlation to mastics' viscoelasticity," International Journal of Pavement Engineering, p. 1575379, 2019. 